\title{
The application of the Global Competence Matrix in a virtual exchange program with US and Brazilian students
}

\section{Ana Cristina Biondo Salomão ${ }^{1}$ and Eduardo Viana da Silva ${ }^{2}$}

\section{Abstract}

his paper presents the details of a virtual exchange project conducted with 14 university students from Brazil and 14 university students from the US during _ the US spring quarter of 2019. This virtual exchange was part of the Teletandem Brasil Project, which has been developed by São Paulo State University (UNESP) in Brazil and aims at promoting cultural and language learning in tandem. Students watched videos about current topics in Brazil and in the US and discussed them with their international partners. After the mediation sessions, the participants analyzed the results of their conversations through the Global Competence Matrix, a set of guidelines created by the US global competence task force in 2011. The results point to the importance of using an educational tool to promote a deeper cultural understanding, which in this paper focused on the issue of feminism in Brazil and in the US.

Keywords: virtual exchange; teletandem Brasil; Global Competence Matrix; language learning; feminism.

1. São Paulo State University (UNESP); ana.salomao@unesp.br; https://orcid.org/0000-0002-1531-8551

2. University of Washington; evsilva@uw.edu; https://orcid.org/0000-0002-3651-3524

How to cite this article: Salomão, A. C. B., \& Viana da Silva, E. (2020). The application of the Global Competence Matrix in a virtual exchange program with US and Brazilian students. Journal of Virtual Exchange, 3(SI-IVEC2019), 1-12. https://doi.org/10.21827/jve.3.35804 


\section{Introduction}

This article analyzes some of the applications of the Global Competence Matrix (Boix Mansilla \& Jackson, 2011) in a language and cultural virtual exchange with 14 Brazilian students from UNESP at the Araraquara campus and 14 US students from the University of Washington at the Seattle campus. The exchange took place during four Skype interactions of 50 minutes each in the US spring quarter of 2019. It involved a discussion of videos in English and Portuguese focusing on feminism and the educational system in Brazil and in the US. The results of the discussions were debriefed after the interactions using the Global Competence Matrix as a guideline.

The virtual exchange detailed in this practice report is part of the Teletandem Brasil Project. This project aims at pairing university students to work collaboratively through videoconference tools fostering cultural and language learning. Each person in the partnership helps his/her partner to learn his/her native language or a language in which he or she is proficient (Telles \& Vassallo, 2006). The term 'tandem' represents a metaphor for collaborative learning through the image of the two persons on a tandem bike having to work collaboratively to successfully ride it together. In the case of language learning, this collaborative work lies on three principles: reciprocity, autonomy, and equality. In this way, partners must be reciprocal in assisting each other to learn, but at the same time autonomous and have equal opportunities for practice (Salomão, 2019).

In order to facilitate the reflections among participants in this virtual exchange and to promote a deeper cultural understanding, the researchers decided to use the Global Competence Matrix as a guide in the mediation sessions. This matrix was developed in 2011 as part of a US global competence task force ${ }^{3}$ and with the collaboration of two US organizations: the Asia Society and the EdSteps Initiative and the Council of Chiefs State School Officers (CCSSO). Both organizations focus on the development of global competent citizens. The main goal of the Asia Society is "to strengthen relationships and promote understanding among the people, leaders, and institutions of the US and Asia” (Boix Mansilla \& Jackson, 2011, p.iii). The CCSSO is formed by public officials in primary and secondary education in the US and its goal is to provide "leadership, advocacy, and technical assistance on major educational issues” (Boix Mansilla \& Jackson, 2011, p.iii).

The US Global Competence Task Force was organized because of the need for training of educators and policymakers on global education, which according to Gardner (2011), is noticeable in the persistence of traditional educational systems and the lack of interdisciplinary initiatives in education. Gardner explains that the perception of a true global education that takes seriously the

3. https://globalocityeducation.weebly.com/global-competence-matrix.html 
customs, values, and priorities of other nations is seen by many as a threat: "Cosmopolitanism, internationalism, and globalism are often considered dangerous concepts or even 'fighting words"” (Boix Mansilla \& Jackson, 2011, pp. x-xi). In less than ten years since this US global competence task force was formed, the political and social situation in the US and in many other countries points to the division of views on global citizenship. Globalism, as Gardener highlighted, is seen nowadays as a threat by many, which is evident in the sharp political and social divisions. The Brexit crisis in the UK and the immigration crisis in the US are examples of this division. In Brazil as well, the term globalism is seen by a large number of people as a 'fighting word', as the political and social climate moves toward a more nationalistic approach to deal with issues of local and global impact. Furthermore, there is a rise of fear mongering toward foreigners on a global scale. The result has been the resurgence of radical social groups that have successfully promoted an ideology of fear, including xenophobia, racism, islamophobia, attacks on the LGBTQI+ groups and to Jewish communities, among other issues, ranging from fake news to the rise of fascism and Nazism.

Given the context described above, we believe there is an emergent need to focus on educational approaches for global competence. Therefore, the language classroom seems to be an ideal place for such an initiative since language students are exposed to other cultures and other nationalities. For the purpose of the cultural exchange described in this article, we follow the concept of global competence as defined by the US global competence task force: "global competence is the capacity and disposition to understand and act on issues of global significance” (Boix Mansilla \& Jackson, 2011, p. xiii). Thus, to become a globally competent citizen, one must have the educational tools and the desire to understand and act on global issues. The concept of global competence is directly related to that of global citizenship. In dealing with issues of local and global impact, Tully (2014) points out that global citizenship looks at the complexity of each issue according to its context, highlighting that "the art of understanding a concept like 'global citizenship' is not the application of a universal rule to particular cases” (p. 4). Furthermore, Tully (2014) defines citizenship as "negotiated practices in which one becomes a citizen through participation" (p. 9). These definitions show a clear connection between global competence and global citizenship, in which both have an element of action/participation. In this sense, effective communication on local and global issues is imperative in order to understand other perspectives, contexts, similarities, and differences. As the virtual exchange described in this report will show, when students have the opportunity to get to know each other at a personal level, they are more inclined to listen to other perspectives. In addition, having an educational tool to facilitate their reflections, such as the Global Competence Matrix, helps to guide students in the discussions and to go deeper into issues of relevance to them. 


\section{The Global Competence Matrix}

The Global Competence Matrix is divided into four categories as below.

- Investigate the World: students investigate the world beyond their immediate environment.

- Recognize Perspectives: students recognize their own and other's perspectives.

- Communicate Ideas: students communicate ideas effectively with diverse audiences.

- Take Action: students translate their ideas and findings into appropriate actions to improve conditions.

The descriptors above provide students with a framework to examine their colleagues' and their own perspectives on issues of relevance to them. In the 'investigate the world' category, students investigate an issue, synthesize the information, analyze it, and formulate their points of view. In the category of 'recognizing perspectives', students are intentional in listening to the perspectives of others as they contextualize their experiences. This intentionality and awareness are also key for the 'communicate ideas' category, in which students reflect on how effective their communication skills are and how to adapt their conversation, depending on the cultural awareness and language proficiency level of their counterpart. For the 'take action' item, participants discuss their engagement on social issues of significance to them and plan together on how to take action.

The Global Competence Matrix also has separate versions focusing on different fields: arts, English language, mathematics, science, social studies, and world languages. This practice report looks into the application of the categories from the main Global Competence Matrix in a virtual exchange dealing with the theme of feminism.

\section{Context}

The virtual exchange described in this practice report was between 14 Brazilian students from a large university in the Southeast region of Brazil, UNESP, and 14 US students at a major university on the Pacific West Coast, UW.

The majority of the participants were young adults from 18 to 24 years of age, but there were a few older students as well. The teletandem virtual exchange program in Brazil is an extracurricular activity, which is also open to the local community, so the Brazilian participants were enrolled in several undergraduate and graduate courses and would come to the computer lab to participate 
in the sessions on their own time. The US students were enrolled in an advanced Portuguese class and participated in the teletandem during their class time in a computer lab at the university. A few of the participants were staff members of UW taking the Portuguese class as auditors and not as degree-seeking students.

All the Brazilian participants received a certificate of participation from their university. The English proficiency level of Brazilian students ranged from beginner to advanced, while most of the US students had an intermediate to advanced level of proficiency in Portuguese and the large majority were Spanish speakers as well. This was either the fifth or the sixth Portuguese class for most of the US students, who had participated in other virtual exchanges between the two institutions prior to the one described in this paper. However, it was the first time that the Global Competence Matrix was used to facilitate the reflections on the virtual exchange.

\section{Objectives}

The overall aim of this virtual exchange project between the Brazilian and US university students was to provide insights into another culture and the possibility of practicing language skills in a foreign language by the discussion of two major topics: feminism and education. For the purpose of this paper, we focused on the theme of feminism. In order to achieve this goal, students' reflections were seen as an essential part of the learning process, for they would support participants to understand the sessions as more than mere chat. The virtual exchange practice without reflection runs the risk of reinforcing stereotypes about culture and language rather than deconstructing them. The Global Competence Matrix was therefore used as a tool for the students to identify the following skills that they were asked to address in their discussions:

- investigate the world;

- recognize perspectives;

- communicate ideas; and

- take action.

\section{Project design}

The teletandem sessions were scheduled during the times of the Portuguese classes at UW while Brazilian students at UNESP registered for the virtual exchange as an extracurricular activity. Each Skype session was 50-minutes long, of which 25 minutes were in Portuguese and the remaining 
25 minutes in English. Students were paired up and they interacted during four sessions. The participants communicated through Skype using a camera and headphones and they were divided into 14 pairs consisting of one Brazilian student and one US student.

In the first two interactions, students became acquainted with each other, while in the third and fourth interaction, they talked about the topics of feminism and the educational systems, based on a selection of videos assigned by instructors. After the virtual exchange, students met in a mediation session, where they shared their opinions and reflected on the conversations, guided by the Global Competence Matrix. The mediation sessions at UNESP, in Brazil, took place right after the virtual exchange and were conducted in Portuguese. At UW, the mediation sessions happened the day after the interaction during the regular Portuguese class and the discussions were mostly in Portuguese with the occasional use of English as needed.

The Global Competence Matrix was used as a guide by students after their first virtual exchange interaction. The goal was to provide participants with the opportunity of getting to know each other first and to establish some rapport before the discussions about social issues. The matrix was presented in English with a translation in Portuguese. Students at UW revised the Portuguese translation in a class exercise, before the matrix was shared with the Brazilian students in both languages. This was an opportunity for the US students to become familiarized with concepts presented in the Global Competence Matrix. In Brazil, the matrix was introduced to students in a mediation session with Teaching Assistants after their first interaction with US students. Unfortunately, the second interaction did not occur because of the class cancellations at UNESP, in reaction to an announcement from the Brazilian Government on budget cuts in institutions of higher education. This social manifestation was a reminder to students of the political turmoil that Brazil was going through. In the third and fourth interactions, students talked about feminism and the educational systems in Brazil and in the US. The topics were chosen in collaboration between the authors of this paper and a Brazilian graduate student of applied linguistics with the goal of reflecting on current issues of relevance to students.

Participants watched a selection of short videos on the topics chosen by the graduate student in Brazil. The material came from a variety of sources available on YouTube (see Appendix 1 for a list of videos that students watched before the interactions). After each interaction, there was a debriefing session. In both cohorts, participants answered a short questionnaire about the topics in the third and fourth interactions, using the Global Competence Matrix to guide them. The questionnaires were written in Portuguese and most participants also answered in writing in Portuguese (see Appendix 2). 
The selection of topics was based on the current news at the time: the \#Metoo movement in the US and the Brazilian counterpart movement \#Deixaelatrabalhar, in addition to the budget cuts on higher education in Brazil. The US cohort also wrote a two-page reflection paper after the four interactions that corresponded to $10 \%$ of the course final grade.

\section{Evaluation and discussion of outcomes}

This virtual exchange program between the Brazilian and the US universities has been successful during its five-year period, which is evident in the students' feedback in both institutions. Nonetheless, we believed that it was time to introduce a theoretical framework in order to facilitate the conversations, especially around 'controversial' topics that were increasingly frequent in the virtual interactions. It was noticeable that many students took the opportunity to ask their international colleagues about their views on the political and social division that has marked their time at the university, referring specifically to issues about the Bolsonaro and Trump presidencies, for example. Students started tracing parallels between the social and political climate in Brazil and in the US. Our rationale was to introduce a theoretical framework, in this case the Global Competence Matrix, with the goal of having an educational tool to help students to conduct their discussions and to reflect on their virtual exchange.

The results of the survey conducted with students indicated that there were more common values among the participants than anticipated. Two questionnaires, written originally in Portuguese and also answered mostly in Portuguese by both cohorts of students, were distributed in the third and fourth interactions (see Appendix 2 for an English version of the questionnaires). The questionnaires in Brazil were answered on a Google Form, while the US students answered them on a paper version in class. Of the 28 participants, 23 answered the survey (14 Brazilians and nine US students).

The first question below was asked in both questionnaires taken about the last two interactions. This discussion of outcomes focuses on the second questionnaire about the topic of feminism.

Which items from the Global Competence Matrix do you believe were relevant in your conversation during this teletandem interaction?

Both US and Brazilian students $(\mathrm{N}=23)$ referred to the detailed descriptors of the matrix, under the 'recognize perspectives' category. One US student in particular noted the importance of recognizing different perspectives according to the social, political, and economic realities. Some participants 
highlighted the need of being respectful when discussing issues with others and the importance of using the appropriate language in order to convey meaning; "articulate and explain the perspectives of other people and recognize and articulate your perspectives about situations” (US student translated by the authors). It seems evident that students were concerned about listening to others and being respectful in the communication process.

In addition to 'recognize perspectives', the categories of 'investigate the world' $(\mathrm{N}=13)$ and 'communicate ideas' ( $\mathrm{N}=12$ ) were also mentioned repeatedly. Some of the Brazilian participants $(\mathrm{N}=4)$ pointed out that all the categories in the matrix were important for global competence, without attributing any particular order of importance. The category of 'take action' was not mentioned as often as the other ones $(\mathrm{N}=4)$. An American student noted that she spoke about the 'take action' item from the Global Competence Matrix with her colleague in Brazil; however, there was not an agreement on how to act on the social issue discussed: "we talked about taking action, but we don't know how" (US student - translation by the authors). The challenge in the 'take action' item is to provide students with opportunities to exercise their citizenship rights. As educators, we believe that we ought to promote the 'take action' category of the matrix, in order to have a positive impact in society. This is an item that will need more pedagogical attention as we conduct future projects.

Table 1 below shows the number of times that students referred to specific descriptors from the matrix out of 23 participants who answered the survey.

\section{Table 1. Number of mentions to specific descriptors of the matrix}

\begin{tabular}{|l|l|l|l|l|}
\hline $\begin{array}{l}\text { Survey on feminism } \\
\text { Question 1 }\end{array}$ & $\begin{array}{l}\text { Investigate } \\
\text { the world }\end{array}$ & $\begin{array}{l}\text { Recognize } \\
\text { perspectives }\end{array}$ & Communicate ideas & Take action \\
\hline Brazilian Students (N=14) & 7 & 7 & 6 & 2 \\
\hline US Students (N=9) & 6 & 5 & 6 & 2 \\
\hline Total number of students (N=23) & 13 & 12 & 12 & 4 \\
\hline
\end{tabular}

Questions 2 and 3 of the surveys were specific to the themes assigned for the discussion. Below is the second question from the survey focusing on feminism.

Are there significant differences between your local reality and the reality of your colleague in another country? Give examples related to the themes selected for this interaction.

Most students mentioned that there are significant differences between Brazil and the US, especially concerning femicide. Students noted that in Brazil the situation is more precarious for women when 
compared to the US. Several participants wrote comments about other issues as well, such as sexism and misogyny. One comment addressed the video of Emma Watson giving a talk at the United Nations in the HeForShe 2014 Campaign. The student explained that the stereotypical views of women as the caregiver and the one with most of the burden of caring for the house chores goes hand in hand with the social pressure on males to be strong and violent. The student then wrote about her perception that women in the US are treated more equally to men when compared to women in South American countries, saying sexism in the US exists, but it is not as strong.

Participants in Brazil also expressed their understanding of this topic by comparing the situation in both countries. One participant stated that even though women all around the world suffer from sexism, violence seems to be stronger in Brazil.

"In the US it seems that women claim more for the right to decide about their own bodies, for example, abortion. Women here in Brazil do it too, but they need to worry about more basic issues like the high rate of femicide” (Brazilian student - translated by the authors).

Some of the comparisons went beyond the US and Brazilian realities, including Mexico and Colombia, given that some of the US students were born and raised in those countries. These comparisons among countries in Latin America and the US enriched some of the conversations and offered several other perspectives on the topic of feminism. There was an overall agreement among these students that social problems in Mexico, Colombia, and Brazil are more similar than those in the US. In addition, one participant referred to the budget cuts for social programs in countries that have transitioned to a less liberal government, as in the case of Brazil and the US. Others wrote directly about their own political realities, saying that they both agree on the negative influence of the Brazilian president Bolsonaro and president Trump on feminist causes.

The few examples described here in the question about the local reality and feminism demonstrate that students were able to specifically refer to the first three categories of the Global Competence Matrix (investigate the world, recognize perspectives, and communicate ideas). The pedagogical support of the videos also had an impact on the conversation by informing students about the feminism cause in Brazil with the video by the Brazilian activist Amelinha Teles, and in particular her explanations about the high rates of femicide in the country. The students' answers in the survey reflect some of the information from the videos. It is noticeable that this pedagogical practice with the Global Competence Matrix and the reflections on the topic enhanced the virtual exchange experience. The following comment from one of the participants shows the level of awareness that the matrix intends to foster. The student is referring to social expectations around women and men: "we live within different cultural and societal norms and expectations, and 
learning how to articulate this to each other as well as how to explain it shapes our actions” (US student).

When dealing with the question on social activism, which would correspond to the 'take action' item from the matrix, there was an impressive level of students' involvement in social issues. Below is the third and last question of the survey on feminism.

Have you participated in any manifestation in favor of a cause? Which one? How was it?

Some students wrote about their participation in the Women's March in the US and anti-Trump marches in Seattle. There was also a group of US international students who mentioned their participation in social justice events in London, France, and Colombia, including a march in London against the election of the Brazilian president, Jair Bolsonaro. In addition, there was one answer that pointed out a student's concern about participating in a rally that could become violent with the intervention of the government. Nonetheless, the question above does not ask for students to identify and create opportunities for collaborative action on the social issue discussed. In a future study, there is the need to address this category more precisely. There is also the need to pay closer attention to the sources used in the videos. For the topic of feminism discussed here, the videos produced by UNICAMP (State University of Campinas, Brazil) and at the UN provided students with a range of legitimate information on the theme, including statistics and points of view from specialists. On the other hand, the topic of education, which was not analyzed in this paper, used videos from less recognized sources, showing educational rankings with a somewhat superficial analysis. As a result, the students' comments did not go into much depth during the virtual exchange.

\section{Conclusions and implications}

Videoconferencing technologies have been used by teachers to establish contact between foreign language learners in order to provide them with opportunities to expand their worldviews and build new social relationships. Even though the contact afforded by virtual exchange interactions is seen by many as a path into developing intercultural competence, it is important to establish specific teaching strategies to connect students' experiential and practical knowledge by adding theoretical support that can lead them to problematize the discussions for deeper understanding of meanings, ideas, perspectives, and possible actions. The use of the Global Competence Matrix as an educational tool appears to have provided scaffolding for students to reflect on issues involving feminism in their conversations in the virtual exchange. The matrix in combination with the videos and the short 
surveys also facilitated the mediation sessions, encouraging students to reflect on their experiences with their teletandem partner.

By addressing specific issues and problematizing them through a structured theoretical frame, the teaching of 21st century skills can be intentionally inserted into the design of the activities proposed. Although there are many ways of conducting virtual cultural and linguistic exchanges, we believe in creating a balance between time for the participants to get to know each other and time for them to discuss issues of local and global significance. By doing that, participants build a relationship with each other, which may challenge their own assumptions about the other culture and even their own. Therefore, when taking into consideration their partners' perspectives, participants negotiate their understanding of local and global issues.

For future exchanges, we suggest that students answer the surveys in their first language, even if the class discussion is conducted in the target language. This way, the students' cultural analysis will not be limited by their level of proficiency in the foreign language. We also suggest the use of surveys focusing on specific aspects of the Global Competence Matrix in order to verify the efficacy of those specific items. For instance, one survey for a given topic could focus on the following categories: 'investigate the world' and 'recognize perspectives', while another survey about another topic could focus on 'communicate ideas' and 'take action'. In the 'take action' item, for example, we could propose a framework that leads students to put their reflection into action, such as the creation of a social media campaign on an issue of global significance. There is also the need of a structured and longitudinal study about the application of the Global Competence Matrix in different kinds of virtual exchange and the articulation of how it enhances reflection and action in collaborative contexts.

\section{References}

Boix Mansilla, V., \& Jackson, A. (2011). Educating for global competence: preparing our youth to engage the world. CCSSO and Asia Society. https://asiasociety.org/files/book-globalcompetence.pdf

Gardner, H. (2011). Preface. In V. Boix \& A. Jackson (Eds), Educating for global competence: preparing our youth to engage the world. CCSSO and Asia Society. https://asiasociety.org/files/book-globalcompetence.pdf

Salomão, A. C. B. (2019). Teletandem and teacher's beliefs about culture and language. International Journal of Computer-Assisted Language Learning and Teaching, 9, 1-18.

Telles, J. A., \& Vassallo, M. L. A. (2006). Foreign language learning in-tandem: theoretical principles and research perspectives. The ESPecialist, 27(1), 83-118.

Tully, J. (2014). On global citizenship. Bloomsbury. 


\section{Appendices}

Appendix 1: Selection of materials for the virtual exchange discussions

\begin{tabular}{|c|c|c|}
\hline Teletandem session & Materials in Portuguese & Materials In English \\
\hline $\begin{array}{l}\text { Third Interaction } \\
\text { Topics: Feminism and Budget } \\
\text { Cuts on Education in Brazil }\end{array}$ & $\begin{array}{l}\text { YouTube Video: } \\
\text { Movimento feminista e a luta das } \\
\text { mulheres - Entrevista com Amelinha } \\
\text { Teles. (Feminist movement and } \\
\text { the women's fight - Interview } \\
\text { with Amelinha Teles) } \\
\text { Source: Faculdade de } \\
\text { Educação da UNICAMP } \\
\text { https://www.youtube.com/watch?time_ } \\
\text { continue=72\&v=V2IxvxThvRU }\end{array}$ & $\begin{array}{l}\text { YouTube Video: Emma Watson } \\
\text { at the HeForShe Campaign } \\
2014 \text { - Official UN Video } \\
\text { Source: United Nations } \\
\text { https://www.youtube.com/ } \\
\text { watch?v=gkjW9PZBRfk }\end{array}$ \\
\hline $\begin{array}{l}\text { Fourth Interaction } \\
\text { Topic: Educational Systems }\end{array}$ & $\begin{array}{l}\text { YouTube Video: } \\
\text { Como funcionam os melhores } \\
\text { sistemas educacionais do mundo? } \\
\text { (How do the best educational } \\
\text { systems in the world work?) } \\
\text { Source: https://www.youtube. } \\
\text { com/watch?v=7ItaCpVg96A }\end{array}$ & $\begin{array}{l}\text { YouTube Video: } \\
\text { Top ten countries with } \\
\text { the best education. } \\
\text { Source: https://www.youtube. } \\
\text { com/watch?v=jiQWtkd1SxI }\end{array}$ \\
\hline
\end{tabular}

Appendix 2: Questionnaires translated to English

\section{Questions for Interaction \#3}

Proposed theme: feminism

1 - Which items from the Global Competence Matrix do you believe were relevant in your conversation during this teletandem interaction?

2 - Are there significant differences between your local reality and the reality of your colleague in another country? Give examples related to the themes selected for this interaction.

3 - Have you participated in any manifestation in favor of a cause? Which one? How was it?

Questions for Interaction \#4

Proposed themes: the educational system in Brazil and in the US

1 - Which items from the Global Competence Matrix do you believe were relevant in your conversation during this teletandem interaction?

2 - Are there significant differences between your local reality and the reality of your colleague in another country? Give examples related to the educational system

3 - Have you studied in a public or private school? How was your experience? 


\section{Virtual Exchange?}

Published by University of Groningen Press | UGP, a not-for-profit press

Groningen, The Netherlands | UGP@rug.nl

(C) 2020 UNICollaboration (collective work)

(C) 2020 by Authors (individual work)

Journal of Virtual Exchange 2020

Edited by Carolin Fuchs and Müge Satar

Special issue edited by Penelope Margaret Orton, Natesha L Smith-Isabell, and Mary Jane Radford Arrow

Publication date: 2020/09/10

Journal of Virtual Exchange (JVE) is an online, open-access, peer-reviewed journal aimed at practitioners and researchers in the field known variously as virtual exchange, telecollaboration, or online intercultural exchange. It is the official journal of UNICollaboration (https://www.UNICollaboration.org/), the international academic organisation dedicated to supporting and promoting telecollaboration and virtual exchange in higher-level education.

Rights. The whole volume is published under the Attribution-NonCommercial-NoDerivatives 4.0 International licence (CC BY-NCND 4.0); individual articles may have a different licence. Under the CC BY-NC-ND licence, the volume is freely available online for anybody to read, download, copy, and redistribute provided that the author(s), editorial team, and publisher are properly cited. Commercial use and derivative works are, however, not permitted.

Disclaimer. University of Groningen Press does not take any responsibility for the content of the pages written by the authors of this article. The authors have recognised that the work described was not published before, or that it was not under consideration for publication elsewhere. While the information in this article is believed to be true and accurate on the date of its going to press, neither UniCollaboration nor University of Groningen Press can accept any legal responsibility for any errors or omissions. Additionally, the publisher makes no warranty, expressed or implied, with respect to the material contained herein. While University of Groningen Press is committed to publishing works of integrity, the words are the authors' alone.

Trademark notice. Product or corporate names may be trademarks or registered trademarks, and are used only for identification and explanation without intent to infringe.

Copyrighted material. Every effort has been made by the editorial team to trace copyright holders and to obtain their permission for the use of copyrighted material in this article. In the event of errors or omissions, please notify the publisher of any corrections that will need to by incorporated in future editions of this article.

Typeset by Research-publishing.net (https://research-publishing.net)

Noto fonts are open source. All Noto fonts are published under the SIL Open Font License, Version 1.1. Noto is a trademark of Google Inc. (https://www.google.com/get/noto/).

ISSN: 2647-4832 (online only)

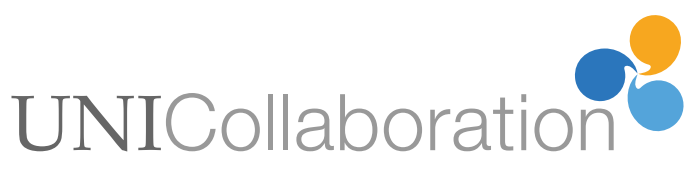

